\title{
Research on Building Insulation and Energy Efficiency
}

\author{
Li Yang ${ }^{1,2, *}$,Zedao $\mathrm{Shi}^{3}$,Wen Qin ${ }^{1,2}$ \\ ${ }^{1,2}$ College of Architecture \& Urban Planning, Tongji University, Key Laboratory of Ecology and Energy Saving Study of Dense Habitat \\ (Tongji University), Ministry of Education, Shanghai, P. R. China ; 3.TongjiArchitecturalDesign (Group) Co.,Ltd )
}

\begin{abstract}
The purpose of this research is to investigate built building envelope renovation methods. Earlier studies on built building renovation have shown that the significant influence of using built building instead of the new building in terms of the energy crisis. However, these have not yet compared various renovation methods for building surface. Therefore, this study classified several reconstruction means into three types and evaluated their performances under three indicators: 1) construction; 2) material; 3) impact on original building appearance. The result shows that the integrated system of insulation and decoration is the best, and the method of additional components is the worst for building enclosure renovation.
\end{abstract}

\section{Introduction}

The building envelope (skin) consists of walls (including non-transparent curtain walls such as metal), doors and windows (including glass curtain walls), exterior parts such as roofing and sunshades component ${ }^{[1-3]}$ (Fig. 1). As an intermediate part connecting the indoor and outdoor, it prevents various unfavourable elements from attacking the building, and brings favourable factors such as light into interior. Currently, there are a large number of built buildings needed to be demolished as they do not meet the thermal insulation requirements. Hence, this study mainly aims at the energy efficiency renovation of the built building envelope and assesses different skin reconstruction patterns from the following three indicators: 1. Construction mode; 2. Material properties; 3. Influence on building appearance.

Currently, developed regions such as the Europe and the United States are in the period of maintenance and renovation of old buildings ${ }^{[4,5]}$. The European and American countries have considered energy renovation of buildings as significant thesis. The implementation for many relevant policies and regulations promote the application of new materials and technologies in building renovation. For example, British architects transformed a batch of office buildings in the 1990s into effectively controlled construction in air conditioners using envelope replacement means.

\section{Method route}

Figure 1 shows the studied method route.

\section{Methodology}

Most of the built buildings envelope can't meet the requirement of function because of being neglected and in disrepair. To determine the appropriate way of reconstruction of the skin, specific measurements should be confirmed according to various impact factors affecting envelope performance. Based on the different locations of renovation construction, the method can be divided into three categories: replacement of decorative materials, external skin, and replacement of the infill.

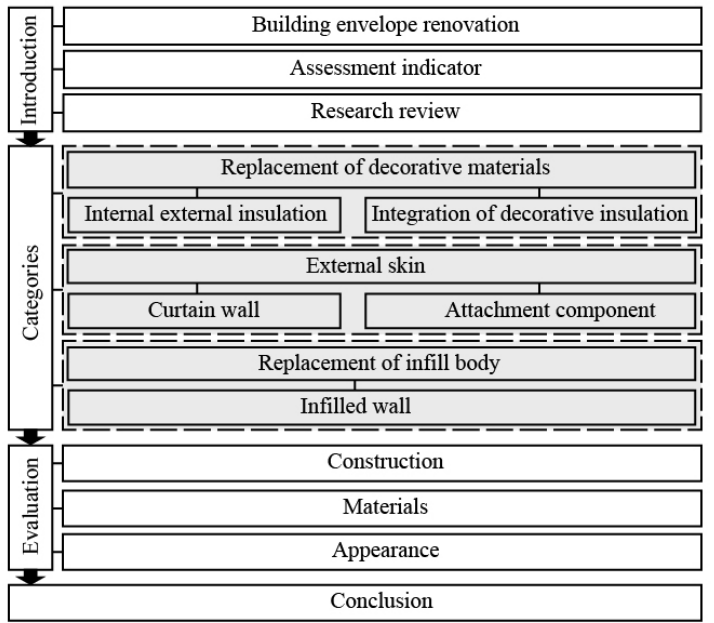

Fig. 1. Research method route

\subsection{Categories}

\subsubsection{Classification of building enclosure reconstruction}

Table 1. Classification of building envelope renovation means.

\begin{tabular}{|l|l|l|}
\hline Categories & Diagram & Instruction \\
\hline
\end{tabular}

\footnotetext{
* Corresponding author: yangli.arch@,tongji.edu.cn
} 


\begin{tabular}{|c|c|c|}
\hline $\begin{array}{l}\text { Replacement } \\
\text { of decorative } \\
\text { materials }\end{array}$ & 2) & $\begin{array}{l}\text { Mainly used in } \\
\text { load bearing } \\
\text { wall structure } \\
\text { building } \\
\text { Change the } \\
\text { color and texture } \\
\text { of the skin, } \\
\text { rarely changing } \\
\text { the shape, and } \\
\text { façade of } \\
\text { architecture }\end{array}$ \\
\hline $\begin{array}{l}\text { External } \\
\text { skin }\end{array}$ & 1) & $\begin{array}{l}\text { Form easily a } \\
\text { gap space, and } \\
\text { enhance the } \\
\text { flexibility of } \\
\text { configuration } \\
\text { Totally change } \\
\text { building original } \\
\text { appearance }\end{array}$ \\
\hline $\begin{array}{l}\text { Replacement } \\
\text { of Infill }\end{array}$ & 2) & $\begin{array}{l}\text { Mainly used in } \\
\text { frame structure } \\
\text { building } \\
\text { Change filling } \\
\text { body of building } \\
\text { walls and } \\
\text { thermal property } \\
\text { Appearance } \\
\text { depend on } \\
\text { requirement }\end{array}$ \\
\hline
\end{tabular}

\subsubsection{Assess method}

This study evaluated various schemes of skin renovation from the following three aspects:

1. Construction: mainly investigating common practices and assembling performance for several means.

2. Material properties: material characteristics and optionality

3. Influence on architectural appearance: The built building is different from the new building. The preservation of the appearance is of vital significance to the architecture value. Hence the degree of influence on the construction outlook via skin reconstruction needs to be evaluated.

\section{Result and discussion}

\subsection{Replacement of decorative materials}

The replacement of decorative materials is mainly performed in building surface operations, without any other external attachment components.

\subsubsection{Internal and external insulation}

Wall insulation technology includes three types: internal insulation, external insulation, and wall self-insulation (sandwich construction). For built building where there is no problem in the safety of the main structure, the original base wall remains for further renovation rather than demolishment. Therefore, the internal insulation and external insulation are generally chosen as renovation measurements.

For external insulation, three layers comprise the whole system, basement layer, insulation layer and decoration layer on the outermost surface.(Fig.2) The insulating material in panel or particle condition such as EPS (polystyrene board) constitutes the insulation layer and connects with the decoration layer through Anchoring or gluing. While insulating tier only employs porous material, the decorative layer could utilize various veneer material based on the built building demand i.e. coating, tile, etc.

External insulation system

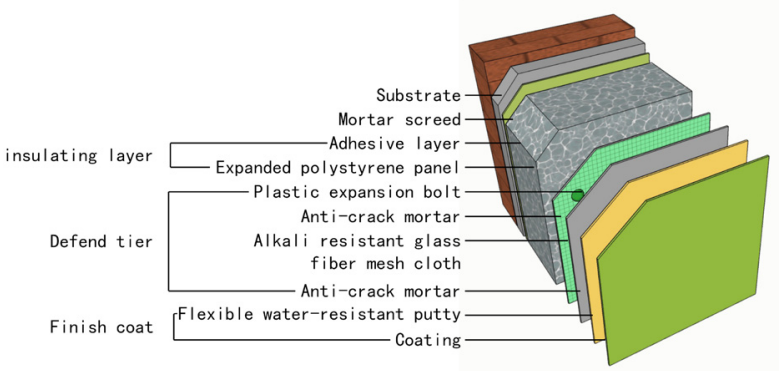

Fig. 2. External insulation construction

Characteristics: 1. Three layers separate with each other integrated with anchoring and gluing. As the limitation in assembly craft, this approach conducts not well in term of assembling. 2. Porous insulation is the only insulated material type in the corresponding layer and various decorative materials can be selected depending on the requirement. 3. For internal and external insulation, as this approach doesn't change the elevation look with no changing the windows and doors positions, the surface layer also could employ materials in accordance with built building requirement, this approach won't influence the building outlook completely.

Internal insulation system

For historical building, the insulated performance can be improved by using the internal insulation system, that is, the porous board or the thermal insulation mortar is adhered to the inside of the enclosure so that to avoid breaking building outlook. This system places the thermal insulation material at the inner side of the enclosing structure, thus material has low requirements on the weather resistance condition.(Fig.3)

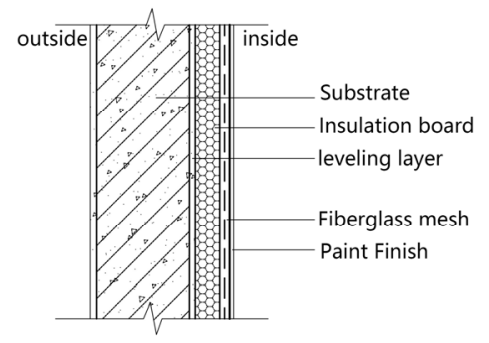

Fig. 3. Internal insulation construction

Characteristics: 1. Whole constructed processes do not affect architecture appearance and have poor 
assembling performance. 2. The internal insulation material is the same as the external system, however, internal material has lower durability than that for external. 3. This internal construction has the smallest effect on the building outlook comparing to other envelope renovation methods.

\subsubsection{Integration of decorative insulation}

In order to meet the higher decoration requirements, the wall renovation can also be integrated with insulation and decoration panels.

The insulating decorative integrated board refers to a composite structure that integrates the heat-insulating board, the reinforcing board, the surface decorative material, and the anchoring structural in a factory. Surface layer uses inorganic sheet or metal panel covering by coating. The thermal insulation decorative board system transforms on-site operations of the conventional constructing technology into the factory, which makes the system manufacture more conveniently and quickly.(Fig.4)
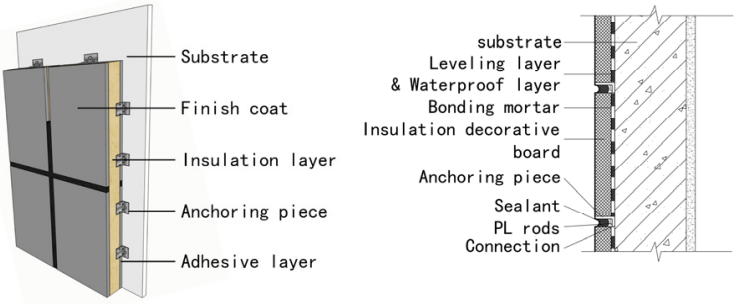

Fig. 4. Integration of decorative insulation construction

Characteristics: 1) The integrated system of decoration with insulation has a higher level of assembling performance than other approaches in the replacement of decorative materials method. 2. Facing material can be replaced as needed. 3) Same as the other two cases in replacement of decorative materials, integrated system of decoration with insulation also perform best in maintaining original architectural appearance.

\subsection{External skin}

\subsubsection{Curtain wall}

Curtain wall construction can be classified into a lightweight curtain wall and heavy double wall based on the material weight. There are two main structures of the components, one is built-in embedded parts in the wall, and directly connects to the surface plate; the other one is the embedded part connecting the steel keel system in combination with veneer via fastenings. Note that while the surface panel could adopt various materials, for example, metal, stone, glass and etc. in which whatever constructions in materials can form a cavity between skin and basement wall. (Fig.5)

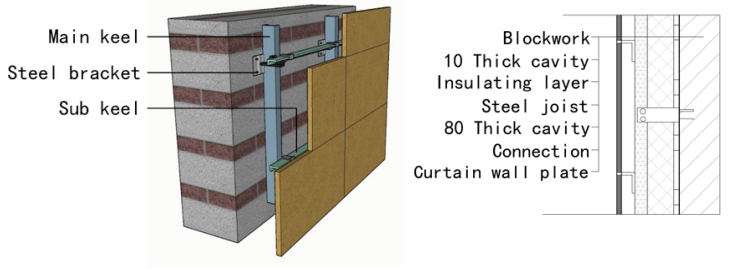

Fig. 5. Curtain wall construction

Characteristics : 1 . Due to a variety of surface decorative panels can be produced in modular, whole curtail wall system has the best performance in assembling condition. 2. Steel keel and slate assembling system provide the possibility for any surface material usage. In addition, the cavity shaped that between panel and wall leads to the improvement in insulation performance for the system. 3. Although this curtain wall construction has good condition in fabrication and material selectivity, it still attaches outside of the original building and destructs architecture appearance totally. In this case, significant historical building envelope renovation can't accept this renovation practice.

\subsubsection{Attachment component}

Attachment component for surface could also be used for building renovation. It includes several forms such as ventilated wall, sun-shading panel, vertical greenery and etc. in terms of different patterns for components. Different components have corresponded functions on built building. For attachment components of planting, for example, building wall temperature and the surrounding thermal environment is reduced via shading and evaporation function of plants to improve comfort level. In the process of implementing the green wall renovation, it is imperative to select plants depending on the climate of the local region and the envelope orientation.

For the high-rise buildings, the module assembly greening method can be adopted in the renovation. Module assembly greening component mode mainly includes bone frame type of container, basin type, planting box type and medium type, all of which are prefabricated unit modules, assembled and combined according to requirements with an irrigation system. Each prefabricated plant can be an independent unit or be linked to each other to form an organic system.(Fig.6)

Characteristics: 1 . The attachment components have the best assembling performance and can be hoisted directly to the site after finished in the factory in advance.

2. Special construction of attachment component dominates materials limitations for this system that only can be used by easy-to-assemble components.

3. Just the same as the curtain wall, attachment components reform the built building and they change the original building appearance totally. 


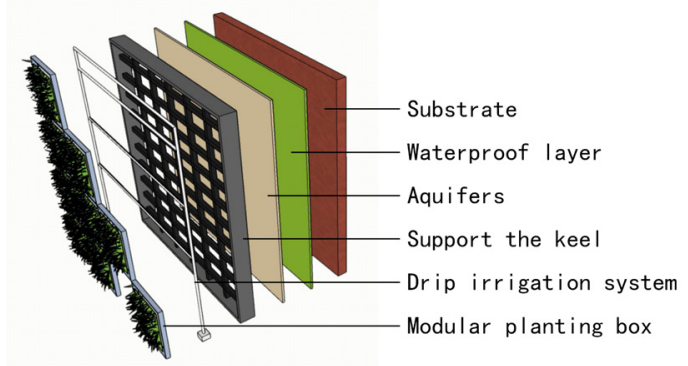

Fig. 6. Attachment planting components

\subsection{Replacement of Infill}

\subsubsection{Three commonly used filling materials}

The insulation performance for the replacement of infill material mainly depends on the property of the infill material itself. Currently used the infill materials mainly include autoclaved aerated concrete block, sintered shale hollow block, and ceramsite-concrete hollow blocks. For this wall type, from outside to inside, the structure is as follows: outer-plastering layer, wall self-insulating material, and inner-plastering layer. At the same time, in order to further improve the thermal performance of the enclosure, a hard polyurethane foam board could put into the centre of the hollow block to further improve the thermal insulation performance of the wall.(Fig.7) As shown in figure 8 , the thermal resistance of the wall and the heat transfer coefficient are plotted as a function of the thickness of the polyurethane.

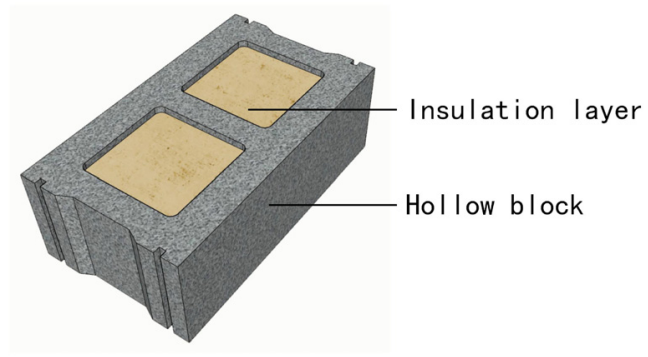

Fig. 7. Infilled wall block with insulation layer
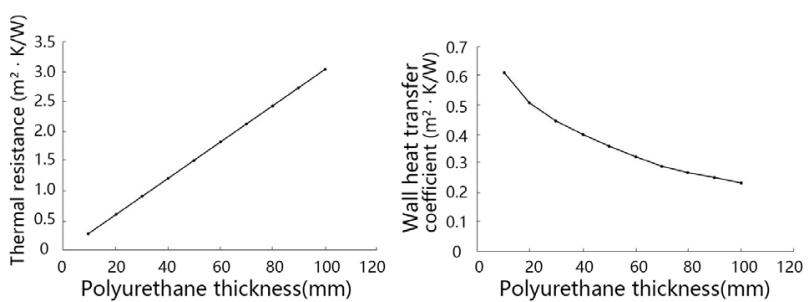

Fig. 8. Attachment planting components

With the increase of the thickness of the polyurethane foam, the thermal resistance of the polyurethane foam enhances, and the thermal resistance of the composite building block is also gradually increased. While the heat transfer coefficient of the wall is significantly reduced. In case of using composite building blocks, changing thickness of polyurethane foam and autoclaved aerated concrete block can meet different requirements for various climatic zones.

Characteristics: 1.The degree of assembly is high, mainly in the way of bonding.

2. Insulation material primary uses for infilled wall with no impact on the building surface material.

3. This method almost has no influence on the appearance of the built building, which is highly recommended for historical building renovation.

\section{Conclusion}

Table 2. Comparison between different reconstruction patterns.

\begin{tabular}{llll}
\hline $\begin{array}{l}\text { Reconstruction } \\
\text { pattern }\end{array}$ & Construction & Material & Appearance \\
\hline $\begin{array}{l}\text { Internal } \\
\text { external } \\
\text { insulation }\end{array}$ & Medium & Medium & Best \\
\hline $\begin{array}{l}\text { Integration of } \\
\text { decorative } \\
\text { insulation }\end{array}$ & Best & Best & Best \\
\hline Curtain wall & Best & Best & Worst \\
\hline $\begin{array}{l}\text { Attachment } \\
\text { component }\end{array}$ & Best & Medium & Worst \\
\hline Infilled wall & Medium & Medium & Best \\
\hline
\end{tabular}

It can be seen from the table that the integrated system of insulation and decoration has the best performance among built building enclosure renovation methods, which not only has a high level of assembly, but has little influence on the appearance of the building. Apart from this, it can also shape the building look in accordance with human needs. In contrary, the worst architecture envelope renovation scheme is the attachment component. Despite having the highest level of assembly trait, it considerably influences the appearance of buildings. Consequently, this means could only be appropriate for buildings with lower look requirements. Internal and exterior insulation system is similar to the replacement of filled wall. Both of them are highly recommended for historical built building reconstruction with the lowest impact on the building appearance. Curtain wall system indicates apparent different characteristics with other methods. It has the highest assembling performance and the smallest limitation of material options. However, it can also change the built building totally and make the construction look like an entirely new building. To sum up, for the envelope renovation of the built building, the integrated system of insulation and decoration is the best, and the method of additional components is the worst.

\section{References}

1. F. Qian, Appl. Mech. Mater, 737(2015)

2. R. Marquez, C. F. M. Coimbra, Solar Energy, 91(2013)

3. W. Richardson, H. Krishnaswami, R. Vega, M. Cervantes, Sustainability, 9(2017) 
4. L. Yang, Green building design: Building energy efficiency, Tongji University Press, Shanghai (2016)

5. Feng Qian, Li Yang. Nature Environment and Pollution Technology, 15(2016) 